\title{
Potential benefits of Yoga in pregnancy- related complications during the COVID-19 pandemic and implications for working
}

\section{women}

\author{
Pooja Nadholta ${ }^{\mathrm{a}}$, Parul Bali ${ }^{\mathrm{b}}$, Amit Singh $^{\mathrm{c}}$ and Akshay Anand ${ }^{\mathrm{a}, *}$ \\ ${ }^{a}$ Neuroscience Research Lab, Post Graduate Institute of Medical Education and Research, Chandigarh, India \\ ${ }^{\mathrm{b}}$ Department of Biophysics, Post Graduate Institute of Medical Education and Research, Chandigarh, India \\ ${ }^{\mathrm{c}}$ Swami Vivekananda Yoga Research Foundation (SVYASA), Bangalore, India
}

Received 30 June 2020

Accepted 16 August 2020

\begin{abstract}
.
BACKGROUND: Pregnancy is a vulnerable period of growth and enrichment along with many physiological and psychological challenges. These changes can lead to complications if compounded by external stress and anxiety. COVID-19 has emerged as a chief stressor among the general population and is a serious threat among vulnerable populations. Therefore, there is a need for stress management tools, such as Yoga and physical exercises, both at home and at work. These can be adopted during the pandemic with proper maintenance of social distancing.

OBJECTIVE: To evaluate and compile literature that has reported the health outcomes of Yoga intervention on pregnancy at the workplace and analyzes both the restrictions as well as advantages of its beneficial effects in comparison to physical exercises.

METHODOLOGY: A comprehensive literature review was conducted utilizing PubMed and Google Scholar. The keywords used for the search include "Yoga", "work", "complications", "physical exercise", "drugs" and "COVID" indifferent permutations and combinations with "pregnancy". We compiled the literature with respect to pregnancy complications and the effects of drugs, physical activity and Yoga for preventing these complications.

RESULTS: We noted that pregnancy-related complications are becoming more prevalent because of a sedentary lifestyle, restricted physical activity and growing stress. In such situations, a home or workplace Yoga protocol can combine both exercise and mindfulness-based alleviation of anxiety for both working and non-working women.

CONCLUSION: Yoga can be effective for combating stress and anxiety besides boosting immunity in pregnant working women confronted with the COVID-19 pandemic.
\end{abstract}

Keywords: Pregnancy, Yoga, mindfulness, COVID-19, meditation

*Address for correspondence: Akshay Anand, PhD., Professor Neuroscience Research Lab Department of Neurology, Post Graduate Institute of Medical Education and Research, Chandigarh, India. Tel.: +91 9914209090; E-mail: akshaylanand@ rediff mail.com.

\section{Introduction}

Pregnancy is associated with physical and emotional changes, which are directly linked to the health of the expectant mother and are detrimental to fetal and maternal health outcomes [1]. Maternal stress 
is associated with pregnancy-related complications such as low birth weight (LBW), preterm labor (PTL), pregnancy-induced hypertension (PIH), and delayed neuropsychological development in affected offspring [2]. Psychological distress, anxiety and depression are already associated with pregnancy and COVID-19 has become an additional stressor during this pandemic, thereby worsening stress, anxiety and further causing sleep disruption among pregnant women [3]. Studies have shown that women tend to develop higher stress during disease outbreak and they are at higher risk of developing depression [4, 5]. The tendency to develop mental distress is higher among pregnant workers during the COVID-19 pandemic as they have to leave home to not only retain their jobs but also to cater to the sick in hospitals. Therefore, novel intervention strategies and protective factors are essential for alleviating psychological distress caused by the uncertainty of COVID-19.

Due to an increasing sedentary lifestyle, a large population is physically inactive either due to availability of maids for household chores, increased hours of on desk work, or traveling to workplaces with leisure time devoted to watching television or spending time on social media [6, 7]. Duration of sitting hours also increase for working pregnant women due to long hours of workplace requirements defined for pregnancy.

Covid-19 is a potentially fatal disease caused by SARS CoV-2 and has become a serious public health issue since December 2019. The virus can get transmitted from person-to-person, which makes it a major threat to human health. The more vulnerable and susceptible populations such as children, the aged, pregnant women, newborns and health care workers (HCW) need additional care during pandemic so that the spread of pandemic can be minimized among this population [8]. Pregnant women have higher propensity of infection as they are more receptive to respiratory pathogens and develop pneumonia more frequently as compared to non-pregnant women [9]. Probability of infection increases when above mentioned vulnerable population is not able to adhere to physical distancing due to work requirements, hospital exposure, travelling etc.

It is also pertinent to note that there is an increased burden on the health care system for providing critical care, with general hospitals being converted into critical care wards [10]. This has further complicated the pregnancy outcomes for working women. In current times, the anxiety and stress is further compounded due to the inability to visit hospitals coupled with fear of being infected by COVID-19 and anticipated transmission of infection to other family members. On the other hand, pregnant HCWs experience increased stress at work for fear of contracting the disease at hospitals coupled with physical stress of wearing PPE in hot and humid tropical environment. In India, this is further complicated by fear of losing employment and shrinking help from house maids [11] as most working women depend on them for their daily chores. Therefore, the control of the COVID19 spread among pregnant women and the potential risk of its vertical transmission has become a subject of raging debate which includes mind management practices.

We propose that prenatal Yoga is a feasible and acceptable intervention for pregnant women with symptoms of anxiety and/or depression [12] and can also be practiced at the workplace. Prenatal Yoga contains all aspects of Yoga, for instance breathing practices (pranayamas), postures (asanas) that can be practiced easily by pregnant women besides meditation (dhayana) [13]. Implementation of Yoga during pregnancy may help to reduce symptoms of stress and anxiety and thereby increases the quality of life $[14,15]$ if adopted by employers for employees at the workplace. A Yoga protocol can be developed and adopted universally during pregnancy.

\section{Effect of COVID-19 on pregnancy}

As mentioned, COVID-19 has become a stressor among general population and pregnant HCWs are more worried for fear of this viral infection that has no treatment so far [16]. Preliminary evidence from available data suggests that anxiety, depression and stress constitute common response to COVID-19. This can be further associated with a disrupted sleep pattern [17]. Pregnant women, children, individuals suffering with chronic obstructive pulmonary disease and the elderly are more susceptible to COVID19 infection [18]. COVID-19-confirmed pregnant women have been shown to have lower counts of WBC, neutrophils, C - reactive protein and transient increase in postpartum blood with premature rupture of membrane (PROM), premature delivery [19].

In hospitals, pregnant women not only worry about neonatal delivery, neonatal care, such as postpartum vaccination, and screening but also its impact on their employment if they get infected [20]. Intrauterine transmission of corona viruses from mother to fetus is low but the risk of adverse pregnancy outcome 


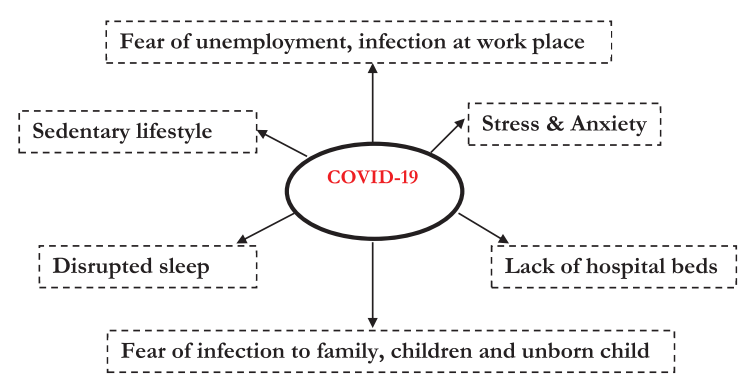

Fig. 1. COVID-19 has become a major stressor among the general population exerting an adverse impact on lifestyle and mental health due to the fear of being infected, unemployment, poor quality of sleep, sedentary lifestyle and stress. These factors may worsen the health of both the mother and fetus.

like preterm delivery, intrauterine growth restriction (IUGR), spontaneous abortion and perinatal death increase after infection [21]. Congenital anomalies associated with COVID-19 remain unknown, adding to the growing anxiety. Usually, viral infections during pregnancy are associated with fetal death, intrauterine infections, congenital malformations, perinatal diseases, mental retardation and cerebral palsy [22].

\section{Pregnancy - A challenge during the pandemic}

Pregnant women experience multiple challenges and varying psychological and emotional distress coupled with physical changes that support the growing fetus [23, 24]. Pregnant HCWs who report to work during pandemic remain anxious due to the inherent risks. As the health of a mother is directly linked with health of fetus, therefore, any unforeseen infection may directly affect the child's health and future employment of the working mother.

In general, many maternal complications including obstructed labor, antepartum hemorrhage (APH), infections, pregnancy-induced hypertension (PIH) and eclampsia also have direct effect on fetal outcome [25]. Hyperlipidemia, i.e. increased lipid concentration in plasma, is common during pregnancy which can lead to coronary heart diseases and other vascular complications [26] and is further compounded by extended lockdown, loss of employment and associated sedentary lifestyle [27].

Metabolic alterations are common during pregnancy and often result in excessive weight gain further compounded by a sedentary lifestyle. Excessive weight gain can cause obesity, which is associated with increased possibilities of developing pelvic floor problems and adverse pregnancy outcomes. These complications can be reduced to some extent by doing general muscle strengthening exercises during pregnancy [28-30]. Respiratory physiology and cardiovascular function are altered to suit the metabolic demands of mother and fetus. For example, the mechanical alteration in chest wall and diaphragm serves to accommodate the developing fetus in uterus [31]. These respiratory changes may induce pregnancy-induced hypertension (PIH), which is a major complication that occurs during pregnancy. This may cause fetal growth retardation, premature delivery, maternal morbidity and mortality and fetal morbidity and mortality $[32,33]$.

\section{The psychological impact of COVID-19 quarantine}

During the ongoing pandemic, the fear of losing job coupled with prolonged home quarantine has promoted boredom and frustration besides causing restlessness due to unpredictable pregnancy outcomes $[34,35]$. The fear of getting infected or transmitting the infection to other members of the family results in increased stress and anxiety of a working mother. These feelings may be negatively associated with systematic inflammation and increased inflammatory response in the body. WHO suggests that meditation and deep breathing can help to remain calm and reduce stress [36]. For this standardized and validated protocols are required. A survey of 1987 pregnant women showed an increased rate of pregnancy-related stress, anxiety and depression. These psychological changes may have long term adverse effects on mother and child [37].

As discussed, the maternal prenatal stress adversely affects fetal development and may be associated with preterm birth and low birth weight and negatively affecting child cognition in later life [38, 39]. Preterm birth (PTB) and low birth weight (LBW) can lead to neonatal and childhood morbidities, mortality, and neuro-developmental impairment and disabilities [40-42]. Prenatal depression and anxiety also affect the fetal brain development and may impact child's socio-behavioral and socio-economic function. Prenatal stress is thought to affect maternal hypothalamic-pituitary-adrenal (HPA) axis, which increases the cortisol in maternal blood flowing through placenta to fetus, impacting fetal development [43]. 
A placental enzyme $11 \beta$-hydroxysteroid dehydrogenase type $2(11 \beta-H S D 2)$ is known to convert active cortisol into inactive cortisone but the level of this enzyme is downregulated during chronic stress resulting in increased exposure of fetus to maternal hormones [44]. Prenatal stress also causes the downregulation of placental $11 \beta-H S D 2$ activity and consequent exposure of the fetus to cortisol. This may obstruct the fetal adrenal growth and maturation characteristic of low birth weight neonates. Prenatal stress or anxiety is also associated with adverse neuro-developmental outcomes, which includes schizophrenia, autism, emotional or behavioral problems and reduced cognitive abilities [45]. It is widely believed that there is an association between adverse outcome and gestational age as various regions of the brain develop at different stages [45].

Khashan et al. suggested that infant born from the women who was exposed to stress during first trimester have more chances of schizophrenia [46]. Autism is also associated with the maternal stress during prenatal period [47]. The corticotropin-releasing hormone (CRH) level in maternal blood plasma increases stress and is considered a potential marker of preterm birth [48]. Chronic stress is associated with pregnant HCWs. This may contribute to preterm births and the rate of anticipated preterm births can be decreased by organized stress reduction strategies such as relaxation, Yoga and mindfulness and appropriate prenatal care [49]. At present, the COVID-19 pandemic is the greatest stressor to the working pregnant women and is anticipated to have a negative impact on maternal and fetal outcome.

\section{Sedentary lifestyle during pregnancy}

Sedentary behavior is not a lack of physical activity but includes activities that utilize less than 1.5 metabolic equivalent energy and do not increase energy expenditure above the resting level. This concerns activities such as sitting, sleeping, lying down and screen-based entertainment such as social media, watching television, and playing online games [50]. Epidemiological studies suggest that more than 50\% of the population spend half of their waking hours in sedentary behavior [51] which may have increased during lockdown. Pregnant women also spend half of the day being sedentary, similar to general population which may be associated with abnormal metabolic changes, abnormal blood pressure, cardio- vascular diseases and GDM [52-54]. More time spent e.g. sitting while watching TV, using social media and no involvement in any kind of physical activity may develop anxiety and depression in expectant mother [55]. This has adverse effects on working pregnant women who have desk sitting jobs and remain devoid of any kind of physical activity. This is further complicated due to availability of maids for household chores. Sedentary behavior is associated with cardiovascular disease, type 2 diabetes, stress, obesity, excessive weight gain and adverse fetal and maternal outcomes including occasional mortality [56].

\section{Effect of medication in pregnancy}

About 2-3\% birth defects are caused by the use of drugs [57]. Earlier pregnant women who took thalidomide during pregnancy gave birth to children with phocomelia and later the teratogenic effects of diethylstilbestrol led to concern about medication during pregnancy. In 1979, the Food and Drug Administration (FDA) sought to examine the teratogenic risk of drugs by obtaining the data from human and animal studies and categorized the pregnancy drugs into different categories [58, 59]. A survey of the French Health Insurance Service on drug prescriptions during pregnancy in southwest France showed that about 99\% women (among 1000 women) received prescription for at least one drug during pregnancy and $1.6 \%$ women get prescription of $\mathrm{X}$ category (e.g. misoprostol (one), clomiphene (three), topical or oral estradiol or oestriol (nine)) drugs (fetal risk outweighs benefits) [60].

According to FDA guidelines, pregnancy drugs are classified on the basis of risk they cause to fetus. Drugs are classified in various categories: A (no risk to the fetus if taken during the first trimestercontrolled studies in women), B (no risk to fetus in animal studies but no controlled studies in human), C (adverse effect on fetus in animal studies but absent controlled studies in human), D (risk for human fetus, but benefits outweighs risk) and X (fetal abnormalities and the risk outweighs benefit) [61]. Nearly all drugs consumed by women during pregnancy, including antidepressants and their metabolites, cross the placenta and reach the fetus [62,63]. Antiepileptic drugs (AEDs) such as Valproate and Phenobarbital are associated with a high risk of major malformation in the fetus and can cause birth deformities if taken during pregnancy [64]. 
Table 1

Categorization of drugs on the basis of their side effects to the mother and fetus as classified by the Food and Drug Administration (FDA) guidelines

\begin{tabular}{|c|c|}
\hline Drug & Side effects \\
\hline Amphetamines & Increased incidences of clefting, cardiac anomalies, and fetal growth reduction [68]. \\
\hline Diethylstilbestrol & $\begin{array}{l}\text { Genetic tract anomalies in young female child with vaginal adenosis, polyps and ridges, uterine anomalies, clear } \\
\text { cell adenocarcinoma of vagina. Infertility in males child [69]. }\end{array}$ \\
\hline Ethanol & $\begin{array}{l}\text { Fetal teratogen, retro micrognathia and ear/preauricular anomalies, cranial and facial malformations, affect brain } \\
\text { and ocular system of infant [70]. }\end{array}$ \\
\hline Para- tri- methadone & $\begin{array}{l}\text { Abortion or malformation, cleft palate, malformed ears, cardiac defects, urogenital malformations, and skeletal } \\
\text { abnormalities [71]. }\end{array}$ \\
\hline Sex steroids & VACTERAL syndrome [72]. \\
\hline Streptomycin & Retardation of growth and pronounced nervous hyper excitability [73]. \\
\hline Tolbutamide & Increased incidences of fetal anomalies [74]. \\
\hline Barbiturates & Abnormal neural and biochemical differentiation of the central nervous system, deficits in learning [75]. \\
\hline Lithium & Cardiac anomalies [76]. \\
\hline
\end{tabular}

The table contains some drugs with their side effects, which are used during pregnancy to reduce associated complications.

During childbearing period, women are at high risk of developing major depressive disorder (MDD), which is associated with adverse maternal health and abnormal fetal growth. The use of selective serotonin reuptake inhibitors (SSRIs), an antidepressant, causes a low APGAR (Appearance, Pulse, Grimace, Activity, and Respiration) score and increases the chances of perinatal complications [65]. Multiple immunological changes occur during pregnancy and immunosuppressive medication taken during the pregnancy can cause adverse effects on the fetus [66]. Therefore, efforts should be directed to minimize the use of drugs during pregnancy for improved fetal outcomes. As majority of drugs used during pregnancy can cross placenta and can be injurious to the fetus during fetal development, therefore, non-pharmacological remedial measures for stressinduced GDM and hypertension are imperative. It is also known that that hypertension and diabetes render a subject vulnerable to COVID-19 infections. Table 1 includes a few drugs prescribed during pregnancy along with the associated anomalies [67].

\section{Importance of physical activity in alleviating pregnancy-related consequences}

Drug consumption should be minimized during pregnancy due to its various side effects and negative impact on mother and fetus. Exercise can be an effective preventive measure for pregnancy-related complications which, in later stages, become a threat to the mother and child. Exercise during pregnancy have numerous health benefits and is safe for maternal and fetal health. Some of the benefits of exercise during pregnancy include the control of excessive weight gain, prevention and control of GDM, reduction of lower back pain complaints and positive effects on maternal mental health and quality of life [77]. Exercise is supposed to be effective in the prevention of GDM, particularly in obese working women who spent most of the time sitting and eating [78]. Physical activity during pregnancy also reduces the chances of GDM [79], excess maternal weight gain [80] and complications during labor for the mother [81] besides improving the stress response in utero and reduced risk of childhood obesity in the fetus [82].

According to the American College of Obstetrics and Gynecology (ACOG) guidelines, if pregnant women are healthy and complication free, they should continue or start doing exercises [83]. Physical exercise during pregnancy is beneficial for both maternal and fetal health and it improves pregnancy outcome by minimizing the risk of developing GDM, preeclampsia (PE) and abnormal fetal growth [84] as explained above. Exercise during pregnancy is also associated with lower chances of preterm delivery, reduction in the rate of cesareans, instrumental deliveries, hypertension and gestational weigh gain (GWG) [85-87] even though the mental component of exercise is rather limited when compared to other mind-body practices [88].

Pregnancy is a period of emotional and physical stress in which expectant mother experiences a lot of changes, abdominal growth and challenges [89]. If a woman is involved in physical exercises during pregnancy, the risk of cesarean delivery is significantly reduced [90], however, the emotional changes during this period are rarely addressed unless supplanted by mindfulness or Yoga protocols. As the current pandemic imposes restrictions on the outdoor physical activity, the working pregnant women are left with few choices on how and when to access a stress 
Table 2

Benefits of regular physical activity during pregnancy

Benefits of doing exercise during pregnancy, which are limited due to the COVID-19 pandemic

- Less physical discomforts (e.g. fatigue, nausea, leg cramps, backache, constipation, round ligament pain, shortness of breath)

- Decreased incidence of complications such as gestational hypertension, preeclampsia and operative delivery

- Controlled blood glucose in GDM

- Reduced stress and anxiety and better sleep

- Increased placental weight along with blood flow and infant birthweight

- Maintenance of fitness level

- Reduced gestational weight gain

- Improved posture

- Faster postpartum recovery

The table contains some of the potential benefits of doing exercise during pregnancy, which include reduction in physical pain, stress, anxiety, excessive weight gain, hypertension and operative delivery along with improving the sleep quality, birth weight and postpartum recovery.

management Yoga protocol in order to alleviate anxiety, phobia and fear. Table 2 shows some of the benefits of doing exercise during pregnancy [91].

In 2002, the American College of Obstetricians and Gynecologists published guidelines for exercise during pregnancy and suggested that any women without pregnancy complication can do moderate exercise for at least 30 minutes a day or most of the days [92]. Gestational hypertension and preeclampsia, excessive gestational weight gain (GWG), GDM and macrosomia (fetus with more birth weight) were found to be decreased after exercise [93]. The above studies show that moderate exercise during pregnancy is good for both maternal and fetal health but intense exercise should be avoided as it may harm the fetus. Hence, the working pregnant women must carefully choose a regimen which includes both mental and physical attributes.

\section{Effect of Yoga during pregnancy}

Yoga is derived from the Sanskrit word "yuj", which means "to yoke and join together". It includes stretching exercises and asana combined with breathing and meditation regimen to unify the emotional, physical and spiritual needs. Yoga has been shown to help reduce stress, anxiety, depression, arthritis, chronic low back, migraine, hypertension and diabetes in adults [94]. As discussed previously, Yoga is a combination of exercises aligned to cer- tain breathing techniques and meditation. It may help overcome the drawbacks of other interventions (drugs and physical activity only) adapted during pregnancy. Yoga does not include any vigorous exercise but slow dynamic and static movements with focused breathing, and controlled stretching; therefore, it is safe during pregnancy.

Yoga practice has been found to improve quality of life by decreasing stress, anxiety and sleep disturbance during pregnancy [95]. Yoga has been shown to be more effective than a standard exercise regimen as it is a good intervention for women who are depressed, at high risk, have lumbo-pelvic pain, or are healthy [96] besides being confined to lockdowns or hospital workplace. Mindfulness Yoga helps to reduce the depression symptoms in pregnant women while improving mental health. It is said to increase the mother's attachment towards her child which is helpful for child's health [97]. Mindfulness and Yoga also regulates eating habits and can benefit glycemic control in pregnant women with GDM [98].

Narendran et al. have shown the effect of Yoga on various pregnancy-related complications and described that the Integrated Yoga Approach during Pregnancy (IYAP) improves birth weight and pregnancy outcomes, and decreases preterm labor (PTL), intra uterine growth restriction (IUGR), low back pain (LBP), pregnancy-induced hypertension (PIH) and other complications associated with pregnancy [99]. Yoga is emerging as an acceptable intervention during pregnancy, not only due to its tremendous benefits during pregnancy, but also due to increased sense of uncertainty of the COVID-19 pandemic which has superimposed a new dimension of anxiety experienced by pregnant HCWs. Other studies have shown that Yoga decreases various pregnancyrelated complications such as preterm labor, IUGR and physical discomforts $[100,101]$. In the absence of outdoor physical activity, Yoga may be effective in reducing the risk factors of prediabetes, obesity and the metabolic syndrome. This may be beneficial in glycaemic control in type 2 diabetes and GDM [102].

In high risk pregnancies, Yoga reduces the stress and is a safe and effective intervention to be adapted [103]. Prenatal Yoga shows significant effect on systolic blood pressure, and the fetal heart rates in primigravida (women who is pregnant for the first time) mothers [104]. As briefly described above, stress has a negative impact on the immune system, rendering a pregnant working women vulnerable to 
infections. Certain twisting Yoga poses are believed to compress and rejuvenate immune organs and channels. It is believed to balance various immune cells by inhibiting the sympathetic aspect of hypothalamus in response to stressful stimuli [105]. In response to stress hypothalamic-pituitary-adrenal (HPA) axis, it activates and hypothalamus thereby producing corticotropin-releasing factor which stimulates the pituitary gland to produce adrenocorticotropin, which leads to the secretion of cortisol [106, 107].

During pregnancy, cortisol level rises continuously as placenta and adrenal both release cortisol [108]. Cortisol is considered as a biomarker of both psychological and physical health [109]. Further, cortisol release during stress reduces cellular immunity, salivary immunoglobulin $(\operatorname{Ig} \mathrm{A})$ and increases the risk of infections. Prenatal Yoga has been shown to reduce cortisol (stress hormone) and enhance the IgA (immune biomarker) during pregnancy [110]. The level of cortisol along with inflammatory cytokine, interleukin (IL)-6 and tumor necrosis factor (TNF) has shown to be decreased after Yoga intervention, while $\beta$-endorphinlevel increases concomitantly [111]. Besides during pregnancy, the Diabetic Yoga Protocol has also been shown to reduce the HbAlc level and stress in pre-diabetic non pregnant women [112]

\section{Does Yoga help in balancing neuropsychological changes during pregnancy?}

Pregnancy is associated with changes in mood and anxiety with marked hormonal fluctuations [113]. This is more pronounced in working mothers as these places are characterized by its own work load and deadlines. Children of depressed mothers are more prone to develop depression and other psychiatric disorders throughout their lifetimes as compared to children of non-depressed mothers. Prenatal Yoga is a feasible intervention for pregnant women with symptoms of anxiety and/or depression [114] and can even be practiced at workplace. Yoga has beneficial effects on cognitive and emotional health and has been shown to improve mental health, decrease anxiety and depression. Yoga improves adaptive autonomic response to stress and reduces perceived stress in healthy pregnant women [115]. For treating depression, Yoga is more acceptable therapy as compared to other standard depression treatments [116]. Mind- body practice, in conjunction with usual care, is much beneficial and cost effective intervention than only usual prenatal care [117].

Corticotropin-releasing hormone $(\mathrm{CRH})$ is released from hypothalamus in response to stress and increased level of CRH during pregnancy is linked to pathogenesis like fetal growth retardation, preterm labor and preeclampsia, which are leading causes of perinatal morbidity and mortality among pregnant women [118]. It is also known that stress can trigger the pro-inflammatory cytokine, TNF $\alpha$ that targets vascular endothelial death and mediates miscarriage by ischemic death of embryo [119]. All these abnormalities are associated with stress and frequency of occurrence of these abnormalities which can be reduced by alleviating stress and depression during pregnancy. Further reducing stress and depression during pregnancy can reduce the frequency of occurrence of these abnormalities. Prenatal Yoga practice has been shown to reduce stress, anxiety, depression symptoms and other uncomfortable experiences related to pregnancy [120] at work or otherwise.

Implementation of Yoga during pregnancy helps to decrease symptoms of stress and anxiety an increases the quality of life $[121,122]$ if implemented by employers at the workplace. Together with usual care, Yoga can empower pregnant women in increasing the quality of life by reducing the uncomfortable experiences, stress, anxiety and depression that are pronounced during the COVID-19 pandemic. It is an effective, useful and recommended intervention, which can be prescribed during pregnancy.

\section{Conclusion}

Mind-body practices have the potential to address both physical and mental attributes and hence it is better, safe and preventive intervention as compared to drugs and physical exercise alone. Therefore, Yoga, along with usual care, can empower pregnant women in increasing the quality of life by reducing the uncomfortable experiences, stress, anxiety and depression that are pronounced during the COVID-19 pandemic. It is an effective, useful and recommended intervention, which can be prescribed during pregnancy. Further research must be carried out to understand the mechanism by which Yoga exerts its influence on mental and physical health. 


\section{Acknowledgments}

We thank Dr. P K Saha for his input and discussions. We acknowledge the Department of Biotechnology, India for the funding of a second author.

\section{Conflict of interest}

None to report.

\section{References}

[1] Hueston WJ, Kasik-Miller S. Changes in functional health status during normal pregnancy. Journal of Family Practice. 1998;47(3):209-12.

[2] Cardwell MS. Stress: pregnancy considerations. Obstetrical \& Gynecological Survey. 2013;68(2):119-29.

[3] Lebel C, MacKinnon A, Bagshawe M, Tomfohr-Madsen L, Giesbrecht G. Elevated depression and anxiety among pregnant individuals during the COVID-19 pandemic.

[4] Lee DT, Sahota D, Leung TN, Yip AS, Lee FF, Chung TK. Psychological responses of pregnant women to an infectious outbreak: a case-control study of the 2003 SARS outbreak in Hong Kong. Journal of Psychosomatic Research. 2006;61(5):707-13.

[5] Wang C, Pan R, Wan X, Tan Y, Xu L, Ho CS, Ho RC. Immediate psychological responses and associated factors during the initial stage of the 2019 coronavirus disease (COVID-19) epidemic among the general population in China. International Journal of Environmental Research and Public Health. 2020;17(5):17

[6] Walsh SM, Meyer MR, Stamatis A, Morgan GB. Why women sit: Determinants of leisure sitting time for working women. Women's Health Issues. 2015;25(6):673-9.

[7] Agrawal P, Gupta K, Mishra V, Agrawal S. Effects of sedentary lifestyle and dietary habits on body mass index change among adult women in India: findings from a follow-up study. Ecology of Food and Nutrition. 2013;52(5):387-406.

[8] Rothan HA, Byrareddy SN. The epidemiology and pathogenesis of coronavirus disease (COVID-19) outbreak. Journal of Autoimmunity. 2020:102433.

[9] Qiao J. What are the risks of COVID-19 infection in pregnant women? The Lancet. 2020;395(10226):760-2.

[10] Xie J, Tong Z, Guan X, Du B, Qiu H, Slutsky AS. Critical care crisis and some recommendations during the COVID19 epidemic in China. Intensive Care Medicine. 2020:1-4.

[11] Arnado JM. Maternalism in mistress-maid relations: The Philippine experience. Journal of international Women's Studies. 2003;4(3):154-77.

[12] Satyapriya M, Nagarathna R, Padmalatha V, Nagendra HR. Effect of integrated yoga on anxiety, depression \& well being in normal pregnancy. Complementary Therapies in Clinical Practice. 2013;19(4):230-6.

[13] Li AW, Goldsmith CA. The effects of yoga on anxiety and stress. Alternative Medicine Review. 2012;17(1).

[14] Jamieson DJ, Theiler RN, Rasmussen SA. Emerging infections and pregnancy. Emerging Infectious Diseases. 2006;12(11):1638.
[15] Li N, Han L, Peng M, Lv Y, Ouyang Y, Liu K, Yue L, Li Q, Sun G, Chen L, Yang L. Maternal and neonatal outcomes of pregnant women with COVID-19 pneumonia: a case-control study. Clinical Infectious Diseases. 2020.

[16] Xiao H, Zhang Y, Kong D, Li S, Yang N. The effects of social support on sleep quality of medical staff treating patients with coronavirus disease 2019 (COVID-19) in January and February 2020 in China. Medical Science Monitor: International Medical Journal of Experimental and Clinical Research. 2020;26:e923549-1.

[17] Rajkumar RP. COVID-19 and mental health: A review of the existing literature. Asian Journal of Psychiatry. 2020;102066.

[18] Duan L, Zhu G. Psychological interventions for people affected by the COVID-19 epidemic. The Lancet Psychiatry. 2020;7(4):300-2.

[19] Li N, Han L, Peng M, Lv Y, Ouyang Y, Liu K, Yue L, Li Q, Sun G, Chen L, Yang L. Maternal and neonatal outcomes of pregnant women with COVID-19 pneumonia: a casecontrol study. Clinical Infectious Diseases. 2020.

[20] Fakari FR, Simbar M. Coronavirus Pandemic and Worries during Pregnancy; a Letter to Editor. Archives of Academic Emergency Medicine. 2020;8(1).

[21] Schwatz DA, Grahan AL. Potential Maternal and Infant Outcomes from Coronavirus 2019-nCoV (SARS-CoV-2) Infecting Pregnant Women: Lessons from SARS, MERS, and Other Human Coronavirus Infections. Viruses. 2020;12(2):194.

[22] Wright Jr HT. Congenital anomalies and viral infections in infants - the etiologic role of maternal viral infections. California Medicine. 1966;105(5):345.

[23] Colman AD, Colman LL. Pregnancy: The psychological experience. New York: Herder and Herder. 1971.

[24] Bailey LA, Hailey BJ. The psychological experience of pregnancy. The International Journal of Psychiatry in Medicine. 1987;16(3):263-74.

[25] Koblinsky MA. Beyond maternal mortality—magnitude, interrelationship and consequences of women's health, pregnancy-related complications and nutritional status on pregnancy outcomes. International Journal of Gynecology \& Obstetrics. 1995;48(Supplement):S21-32.

[26] Qureshi IA, Xi XR, Limbu YR, Bin HY, Chen MI. Hyperlipidaemia during normal pregnancy, parturition and lactation. Annals of the Academy of Medicine, Singapore. 1999;28(2):217-21.

[27] Holm K, Penckofer S, Keresztes P, Biordi D, Chandler P. Coronary artery disease in women: assessment, diagnosis, intervention, and strategies for life style change. AWHONN's Clinical Issues in Perinatal and Women's Health Nursing. 1993;4(2):272-85.

[28] Baeten JM, Bukusi EA, Lambe M. Pregnancy complications and outcomes among overweight and obese nulliparous women. American Journal of Public Health. 2001;91(3):436.

[29] Barakat R, Pelaez M, Montejo R, Luaces M, Zakynthinaki $M$. Exercise during pregnancy improves maternal health perception: a randomized controlled trial. American Journal of Obstetrics and Gynecology. 2011;204(5): 402-e1.

[30] Sengupta PA. The bliss yoga inculcates during the different stages of pregnancy. Int $\mathrm{J}$ Pharm Pharm Sci. 2014;6(10):86-7.

[31] Hegewald MJ, Crapo RO. Respiratory physiology in pregnancy. Clinics in Chest Medicine. 2011;32(1):1-3. 
[32] Zhang J, Zeisler J, Hatch MC, Berkowitz G. Epidemiology of pregnancy-induced hypertension. Epidemiologic Reviews. 1997;19(2):218-32

[33] Kamath U, Rao G, Kamath SU, Rai L. Maternal and fetal indicators of oxidative stress during pregnancy-induced hypertension (PIH). Intern J Appl Biol Pharmaceut Technol. 2011;2(1):405-10.

[34] Brooks SK, Webster RK, Smith LE, Woodland L, Wessely S, Greenberg N, Rubin GJ. The psychological impact of quarantine and how to reduce it: rapid review of the evidence. The Lancet. 2020.

[35] Knopf A. Importance of helping pregnant women with SUDs. The Brown University Child and Adolescent Behavior Letter. 2020;36(7):9-10.

[36] DiGiovanni C, Conley J, Chiu D, Zaborski J. Factors influencing compliance with quarantine in Toronto during the 2003 SARS outbreak. Biosecurity and Bioterrorism: Biodefense Strategy, Practice and Science. 2004;2(4): 265-72.

[37] Lebel C, MacKinnon A, Bagshawe M, Tomfohr-Madsen L, Giesbrecht G. Elevated depression and anxiety among pregnant individuals during the COVID-19 pandemic.

[38] Grote NK, Bridge JA, Gavin AR, Melville JL, Iyengar S, Katon WJ. A meta-analysis of depression during pregnancy and the risk of preterm birth, low birth weight, and intrauterine growth restriction. Archives of General Psychiatry. 2010;67(10):1012-24.

[39] Tarabulsy GM, Pearson J, Vaillancourt-Morel MP, Bussières EL, Madigan S, Lemelin JP, Duchesneau AA, Hatier DE, Royer F. Meta-analytic findings of the relation between maternal prenatal stress and anxiety and child cognitive outcome. Journal of Developmental \& Behavioral Pediatrics. 2014;35(1):38-43.

[40] Swamy GK, Østbye T, Skjærven R. Association of preterm birth with long-term survival, reproduction, and nextgeneration preterm birth. Jama. 2008;299(12):1429-36.

[41] Wilson-Costello D, Friedman H, Minich N, Fanaroff AA, Hack M. Improved survival rates with increased neurodevelopmental disability for extremely low birth weight infants in the 1990s. Pediatrics. 2005;115(4):9971003.

[42] Allen MC, Jones JM. Medical complications of prematurity. Obstetrics and Gynecology. 1986;67(3):427-37.

[43] Madigan S, Oatley H, Racine N, Fearon RP, Schumacher L, Akbari E, Cooke JE, Tarabulsy GM. A meta-analysis of maternal prenatal depression and anxiety on child socioemotional development. Journal of the American Academy of Child \& Adolescent Psychiatry. 2018;57(9):645-57.

[44] Welberg LA, Thrivikraman KV, Plotsky PM. Chronic maternal stress inhibits the capacity to up-regulate placental $11 \beta$-hydroxysteroid dehydrogenase type 2 activity. Journal of Endocrinology. 2005;186(3):R7-12.

[45] O'donnell K, O'connor TG, Glover V. Prenatal stress and neurodevelopment of the child: focus on the HPA axis and role of the placenta. Developmental Neuroscience. 2009;31(4):285-92.

[46] Khashan AS, Abel KM, McNamee R, Pedersen MG, Webb RT, Baker PN, Kenny LC, Mortensen PB. Higher risk of offspring schizophrenia following antenatal maternal exposure to severe adverse life events. Archives of General Psychiatry. 2008;65(2):146-52.

[47] Kinney DK, Miller AM, Crowley DJ, Huang E, Gerber E. Autism prevalence following prenatal exposure to hurricanes and tropical storms in Louisiana. Journal of Autism and Developmental Disorders. 2008;38(3):481-8.
[48] Hobel CJ, Dunkel-Schetter C, Roesch SC, Castro LC, Arora CP. Maternal plasma corticotropin-releasing hormone associated with stress at 20 weeks' gestation in pregnancies ending in preterm delivery. American Journal of Obstetrics and Gynecology. 1999;180(1):S257-63.

[49] Straub H, Qadir S, Miller G, Borders A. Stress and stress reduction. Clinical Obstetrics and Gynecology. 2014;57(3):579-606.

[50] Pate RR, O'neill JR, Lobelo F. The evolving definition of" sedentary". Exercise and Sport Sciences Reviews. 2008;36(4):173-8.

[51] Spittaels H, Van Cauwenberghe E, Verbestel V, De Meester F, Van Dyck D, Verloigne M, Haerens L, Deforche B, Cardon G, De Bourdeaudhuij I. Objectively measured sedentary time and physical activity time across the lifespan: a cross-sectional study in four age groups. International Journal of Behavioral Nutrition and Physical Activity. 2012;9(1):149.

[52] Evenson KR, Wen F. Prevalence and correlates of objectively measured physical activity and sedentary behavior among US pregnant women. Prev Med. 2011;53(1-2):39-43. doi: 10.1016/j.ypmed.2011.04.014

[53] Healy GN, Dunstan DW, Salmon JO, Shaw JE, Zimmet PZ, Owen N. Television time and continuous metabolic risk in physically active adults. Medicine and Science in Sports and Exercise. 2008;40(4):639-45.

[54] Zhang C, Solomon CG, Manson JE, Hu FB. A prospective study of pregravid physical activity and sedentary behaviors in relation to the risk for gestational diabetes mellitus. Archives of Internal Medicine. 2006;166(5):543-8.

[55] Fazzi C, Saunders DH, Linton K, Norman JE, Reynolds RM. Sedentary behaviours during pregnancy: a systematic review. International Journal of Behavioral Nutrition and Physical Activity. 2017;14(1):32.

[56] de Wit L, van Straten A, Lamers F, Cuijpers P, Penninx B. Are sedentary television watching and computer use behaviors associated with anxiety and depressive disorders? Psychiatry Research. 2011;186(2-3):239-43.

[57] Porter RS, editor. The Merck Manual's Online Medical Library. Whitehouse Station: Merck Research Lab. 2004.

[58] Pangle BL. Drugs in Pregnancy and Lactation. In: Herfindal ET, Gourley DR, editors. Text book of Therapeutics, Drug and Disease Management. 8th ed. Philadelphia: Lippincott William Wilkins. 2006. pp. 434-48.

[59] Melton MW. Take two Aspirin or not? Risk of medication use during pregnancy. Mother Baby J. 1999;4: 25-32.

[60] Lacroix I, Damase-Michel C, Lapeyre-Mestre M, Montastruc JL. Prescription of drugs during pregnancy in France. The Lancet. 2000;356(9243):1735-6.

[61] Briggs GG, Freeman RK, Yaffe SJ. Drugs in pregnancy and lactation: a reference guide to fetal and neonatal risk, 4th edn. Baltimore: Williams and Wilkins, 1994:975.

[62] Heikinen T, Ekblad U, Laine K. Transplacental transfer of amitriptyline and nortriptyline in isolated perfused human placenta. Psychopharmacology. 2001;153:450-4

[63] Hernandez-Diaz S, Smith CR, Shen A, Mittendorf R, Hauser WA, Yerby M, Holmes LB. Comparative safety of antiepileptic drugs during pregnancy. Neurology. 2012;78(21):1692-9.

[64] Casper RC, Fleisher BE, Lee-Ancajas JC, Gilles A, Gaylor E, DeBattista A, Hoyme HE. Follow-up of children of depressed mothers exposed or not exposed to antidepressant drugs during pregnancy. The Journal of Pediatrics. 2003;142(4):402-8. 
[65] Bermas BL, Hill JA. Effects of immunosuppressive drugs during pregnancy. Arthritis \& Rheumatism. 1995;38(12): 1722-32.

[66] Einarson A, Selby P, Koren G. Abrupt discontinuation of psychotropic drugs during pregnancy: fear of teratogenic risk and impact of counselling. Journal of Psychiatry and Neuroscience. 2001;26(1):44.

[67] Parboosingh J. The effects of medication during pregnancy. Canadian Family Physician. 1981;27:1013.

[68] Plessinger MA. Prenatal exposure to amphetamines: risks and adverse outcomes in pregnancy. Obstetrics and Gynecology Clinics of North America. 1998;25(1):119-38.

[69] Kinch RA. Diethylstilbestrol in pregnancy: an update. Canadian Medical Association Journal. 1982;127(9): 812.

[70] Iveli MF, Morales S, Rebolledo A, Savietto V, Salemme S, Apezteguía M, Cecotti N, Drut R, Milesi V. Effects of light ethanol consumption during pregnancy: increased frequency of minor anomalies in the newborn and altered contractility of umbilical cord artery. Pediatric Research. 2007;61(4):456-61.

[71] Feldman GL, Weaver DD, Lovrien EW. The fetal trimethadione syndrome: report of an additional family and further delineation of this syndrome. American Journal of Diseases of Children. 1977;131(12):1389-92.

[72] Lammer EJ, Cordero JF, Khoury MJ. Exogenous sex hormone exposure and the risk for VACTERL association. Teratology. 1986;34(2):165-9.

[73] Rubin A, Winston J, Rutledge ML. Effects of streptomycin upon the human fetus. AMA American Journal of Diseases of Children. 1951;82(1):14-6.

[74] Smoak IW. Teratogenic effects of tolbutamide on earlysomite mouse embryos in vitro. Diabetes Research and Clinical Practice. 1992;17(3):161-7.

[75] Reinisch JM, Sanders SA. Early barbiturate exposure: The brain, sexually dimorphic behavior and learning. Neuroscience \& Biobehavioral Reviews. 1982;6(3):311-9.

[76] Weinstein MR, Goldfield MD. Cardiovascular malformations with lithium use during pregnancy. The American Journal of Psychiatry. 1975.

[77] Nascimento SL, Surita FG, Godoy AC, Kasawara KT, Morais SS. Physical activity patterns and factors related to exercise during pregnancy: a cross sectional study. PloS One. 2015;10(6).

[78] Dye TD, Knox KL, Artal R, Aubry RH, Wojtowycz MA. Physical activity, obesity, and diabetes in pregnancy. Am J Epidemiol. 1997;146:961-965

[79] Dempsey JC, Butler CL, Sorensen TK, Lee IM, Thompson ML, Miller RS, Frederick IO, Williams MA. A casecontrol study of maternal recreational physical activity and risk of gestational diabetes mellitus. Diabetes Research and Clinical Practice. 2004;66(2):203-15.

[80] Little KD. Effect of recreational exercise on pregnancy weight gain and subcutaneous fat deposition. Medicine and Science in Sports and Exercise. 1995;27(2):170-7.

[81] Clapp III JF. The course of labor after endurance exercise during pregnancy. American Journal of Obstetrics and Gynecology. 1990;163(6):1799-805.

[82] Clapp III JF. Exercise during pregnancy: a clinical update. Clinics in Sports Medicine. 2000;19(2):273-86.

[83] Committee on Obstetric Practice. ACOG committee opinion. Exercise during pregnancy and the postpartum period. Number 267, January 2002. American College of Obstetricians and Gynecologists. International Journal of Gynaecology and Obstetrics: The Official Organ of the
International Federation of Gynaecology and Obstetrics. 2002;77(1):79.

[84] Mudd LM, Owe KM, Mottola MF, Pivarnik JM. Health benefits of physical activity during pregnancy: an international perspective. Med Sci Sports Exerc. 2013;45(2): 268-77.

[85] Barakat R, Pelaez M, Montejo R, Refoyo I, Coteron J. Exercise throughout pregnancy does not cause preterm delivery: a randomized, controlled trial. Journal of Physical Activity and Health. 2014;11(5):1012-7.

[86] Barakat R, Pelaez M, Lopez C, Montejo R, Coteron J. Exercise during pregnancy reduces the rate of cesarean and instrumental deliveries: results of a randomized controlled trial. The Journal of Maternal-Fetal \& Neonatal Medicine. 2012;25(11):2372-6.

[87] Barakat R, Pelaez M, Cordero Y, Perales M, Lopez C, Coteron J, Mottola MF. Exercise during pregnancy protects against hypertension and macrosomia: randomized clinical trial. American Journal of Obstetrics and Gynecology. 2016;214(5):649-e1.

[88] Siddarth D, Siddarth P, Lavretsky H. An observational study of the health benefits of yoga or tai chi compared to aerobic exercise in community-dwelling middle-aged and older adults. The American Journal of Geriatric Psychiatry: Official Journal of the American Association for Geriatric Psychiatry. 2014;22(3):272.

[89] Colman AD, Colman LL. Pregnancy: The psychological experience. New York: Herder and Herder; 1971.

[90] Domenjoz I, Kayser B, Boulvain M. Effect of physical activity during pregnancy on mode of delivery. American Journal of Obstetrics and Gynecology. 2014;211(4): 401-e1.

[91] Olson D, Sikka RS, Hayman J, Novak M, Stavig C. Exercise in pregnancy. Current Sports Medicine Reports. 2009;8(3):147-53.

[92] Zavorsky GS, Longo LD. Exercise guidelines in pregnancy. Sports Medicine. 2011;41(5):345-60.

[93] Wallace AM, Engstrom JL. The effects of aerobic exercise on the pregnant woman, fetus, and pregnancy outcome: A review. Journal of Nurse-Midwifery. 1987;32(5):277-90.

[94] Field T. Yoga clinical research review. Complementary Therapies in Clinical Practice. 2011;17(1):1-8.

[95] Babbar S, Parks-Savage AC, Chauhan SP. Yoga during pregnancy: a review. American Journal of Perinatology. 2012;29(06):459-64.

[96] Jiang Q, Wu Z, Zhou L, Dunlop J, Chen P. Effects of yoga intervention during pregnancy: a review for current status. American Journal of Perinatology. 2015;32(06):503-14.

[97] Muzik M, Hamilton SE, Rosenblum KL, Waxler E, Hadi Z. Mindfulness yoga during pregnancy for psychiatrically at-risk women: preliminary results from a pilot feasibility study. Complementary Therapies in Clinical Practice. 2012;18(4):235-40

[98] Youngwanichsetha S, Phumdoung S, Ingkathawornwong $\mathrm{T}$. The effects of mindfulness eating and yoga exercise on blood sugar levels of pregnant women with gestational diabetes mellitus. Applied Nursing Research. 2014;27(4):227-30.

[99] Narendran S, Nagarathna R, Narendran V, Gunasheela S, Nagendra HR. Efficacy of yoga on pregnancy outcome. Journal of Alternative \& Complementary Medicine. 2005;11(2):237-44.

[100] Beddoe AE, Yang CP, Kennedy HP, Weiss SJ, Lee KA. The effects of mindfulness-based yoga during pregnancy on maternal psychological and physical distress. 
Journal of Obstetric, Gynecologic \& Neonatal Nursing. 2009;38(3):310-9.

[101] Buttner MM, Brock RL, O’Hara MW, Stuart S. Efficacy of yoga for depressed postpartum women: a randomized controlled trial. Complementary Therapies in Clinical Practice. 2015;21(2):94-100.

[102] Naik D, Thomas N. Yoga-a potential solution for diabetes \& metabolic syndrome. The Indian Journal of Medical Research. 2015;141(6):753.

[103] Deshpande CS, Rakshani A, Nagarathna R, Ganpat TS, Kurpad A, Maskar R, Sudheer DC, Nagendra HR, Abbas R, Raghuram N, Anura K. Yoga for High-Risk Pregnancy: A Randomized Controlled Trial. Annals of Medical and Health Sciences Research. 2013;3(3):341-4.

[104] Hamdiah H, Suwondo A, Hardjanti TS, Soejoenoes A, Anwar MC. Effect of prenatal yoga on anxiety, blood pressure, and fetal heart rate in primigravida mothers. Belitung Nursing Journal. 2017;3(3):246-54.

[105] Arora S, Bhattacharjee J. Modulation of immune responses in stress by Yoga. International Journal of Yoga. 2008;1(2):45.

[106] Waffarn F, Davis EP. Effects of antenatal corticosteroids on the hypothalamic-pituitary-adrenocortical axis of the fetus and newborn: experimental findings and clinical considerations. American Journal of Obstetrics and Gynecology. 2012;207(6):446-54.

[107] Chida Y, Steptoe A. Cortisol awakening response and psychosocial factors: a systematic review and meta-analysis. Biological Psychology. 2009;80(3):265-78.

[108] O'Donnell K, O'Connor TG, Glover V. Prenatal stress and neurodevelopment of the child: focus on the HPA axis and role of the placenta. Dev Neurosci. 2009;31(4):285-292

[109] An K, Starkweather A, Sturgill JL, et al. State of the science: salivary biomarker utilization for stress research. Perspect Nurs Sci. 2014;11(6):87-93

[110] Chen PJ, Yang L, Chou CC, Li CC, Chang YC, Liaw JJ. Effects of prenatal yoga on women's stress and immune function across pregnancy: A randomized controlled trial. Complementary Therapies in Medicine. 2017;31:109-17.

[111] Yadav RK, Magan D, Mehta N, Sharma R, Mahapatra SC. Efficacy of a short-term yoga-based lifestyle intervention in reducing stress and inflammation: preliminary results. The Journal of Alternative and Complementary Medicine. 20121;18(7):662-7.
[112] Singh AK, Kaur N, Kaushal S, Tyagi R, Mathur D, Sivapuram MS, Metri K, Bammidi S, Podder V, Modgil S, Khosla R. Partitioning of radiological, stress and biochemical changes in pre-diabetic women subjected to Diabetic Yoga Protocol. Diabetes \& Metabolic Syndrome: Clinical Research \& Reviews. 2019;13(4):2705-13

[113] Sanna E, Mostallino MC, Murru L, Carta M, Talani G, Zucca S, Mura ML, Maciocco E, Biggio G. Changes in expression and function of extrasynaptic GABAA receptors in the rat hippocampus during pregnancy and after delivery. Journal of Neuroscience. 2009;29(6):1755-65.

[114] Davis K. The feasibility of yoga in the treatment of antenatal depression and anxiety: A pilot study.

[115] Satyapriya M, Nagendra HR, Nagarathna R, Padmalatha V. Effect of integrated yoga on stress and heart rate variability in pregnant women. International Journal of Gynecology \& Obstetrics. 2009;104(3):218-22.

[116] Battle CL, Uebelacker LA, Magee SR, Sutton KA, Miller IW. Potential for prenatal yoga to serve as an intervention to treat depression during pregnancy. Women's Health Issues. 2015;25(2):134-41.

[117] Beddoe AE, Lee KA. Mind-body interventions during pregnancy. Journal of Obstetric, Gynecologic \& Neonatal Nursing. 2008;37(2):165-75.

[118] Tian L, Philp JA, Shipston MJ: Glucocorticoid block of protein kinase $\mathrm{C}$ signalling in mouse pituitary corticotroph AtT20 D16:16 cells. J Physiol. 1999;516:757-768. 16. Gatti G

[119] Krishnan L, Guilbert L, Russell AS, Wegmann TG, Mosmann TR, Belosevic M: Pregnancy impairs resistance of C57BL/6 mice to Leishmania major infection and causes decreased antigen-specific IFN-gamma response and increased production of $\mathrm{T}$ helper 2 cytokines. $\mathrm{J}$ Immunol. 1996;156:644-652.

[120] Bershadsky S, Trumpfheller L, Kimble HB, Pipaloff D, Yim IS. The effect of prenatal Hatha yoga on affect, cortisol and depressive symptoms. Complementary therapies in clinical practice. 2014;20(2):106-13.

[121] Satyapriya M, Nagarathna R, Padmalatha V, Nagendra HR. Effect of integrated yoga on anxiety, depression \& well being in normal pregnancy. Complementary Therapies in Clinical Practice. 2013;19(4):230-6.

[122] Li AW, Goldsmith CA. The effects of yoga on anxiety and stress. Alternative Medicine Review. 2012;17(1). 